\title{
Copper Nanoparticles Embedded in Natural Plagioclase Mineral Crystals: In situ Formation and Third-Order Nonlinearity
}

\author{
Qingchao Zhoul, ${ }^{1 *}$, Chengsi Wang ${ }^{1}$, Andy Hsitien Shen ${ }^{1 *}$ \\ ${ }^{1}$ Gemmological Institute, China University of Geosciences, Wuhan, Hubei \\ 430074, China \\ ${ }^{2}$ School of Jewlery, West Yunnan University of Applied Sciences, Tengchong, \\ Yunnan 679100, China
}

*Email:ahshen@foxmail.com (A.H.); zhouqc229@163.com (Q.C.)

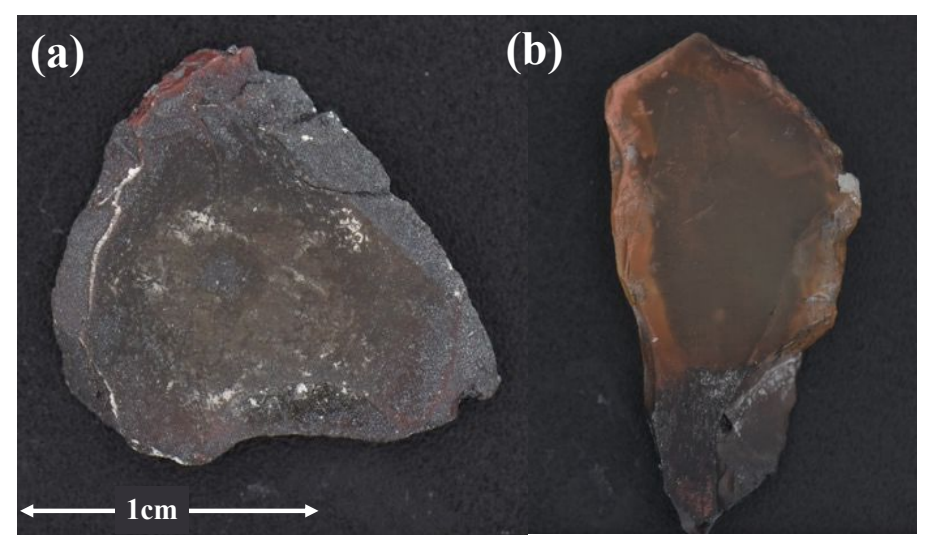

Figure S1. Appearance of plagioclase crystals after high-temperature diffusion, (a) the fully buried one; (b) the partially buried one. 


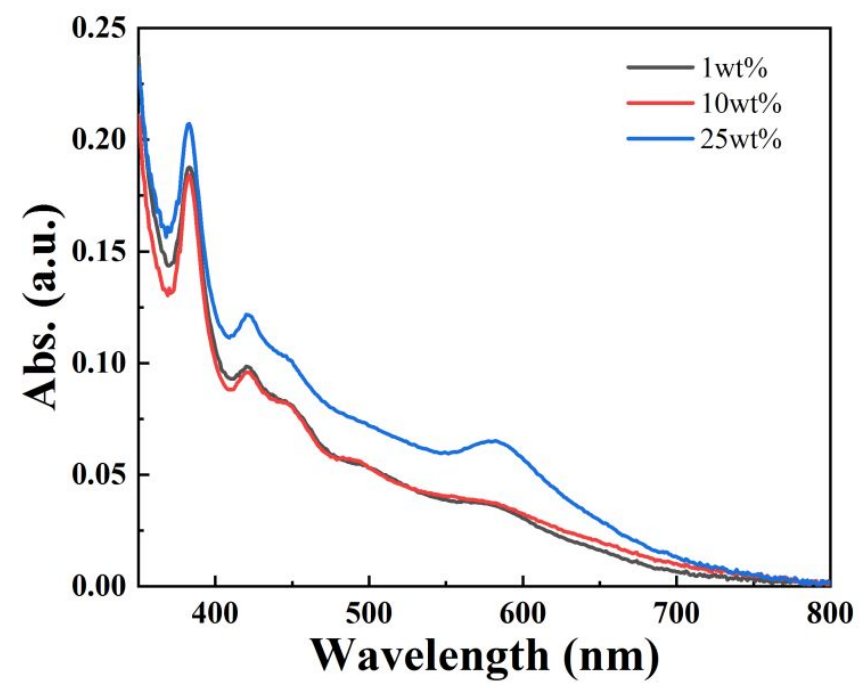

Figure S2. UV-Vis absorption spectra of the plagioclase crystals with diffusion treatment at $1050^{\circ} \mathrm{C}$ for $6 \mathrm{~h}$.

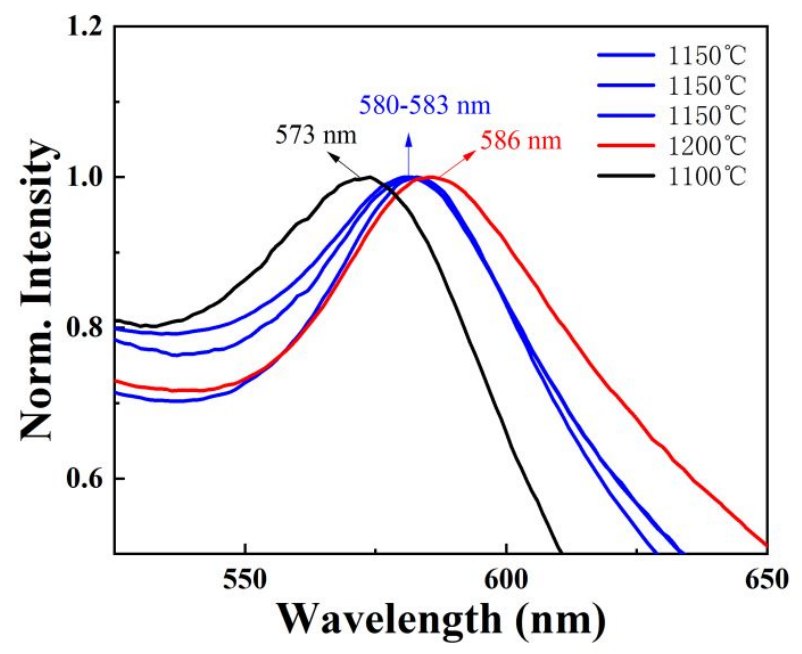

Figure S3. SPR absorption peaks of the $\mathrm{Cu}$ NPs-embedded plagioclase crystals obtained in different temperatures.
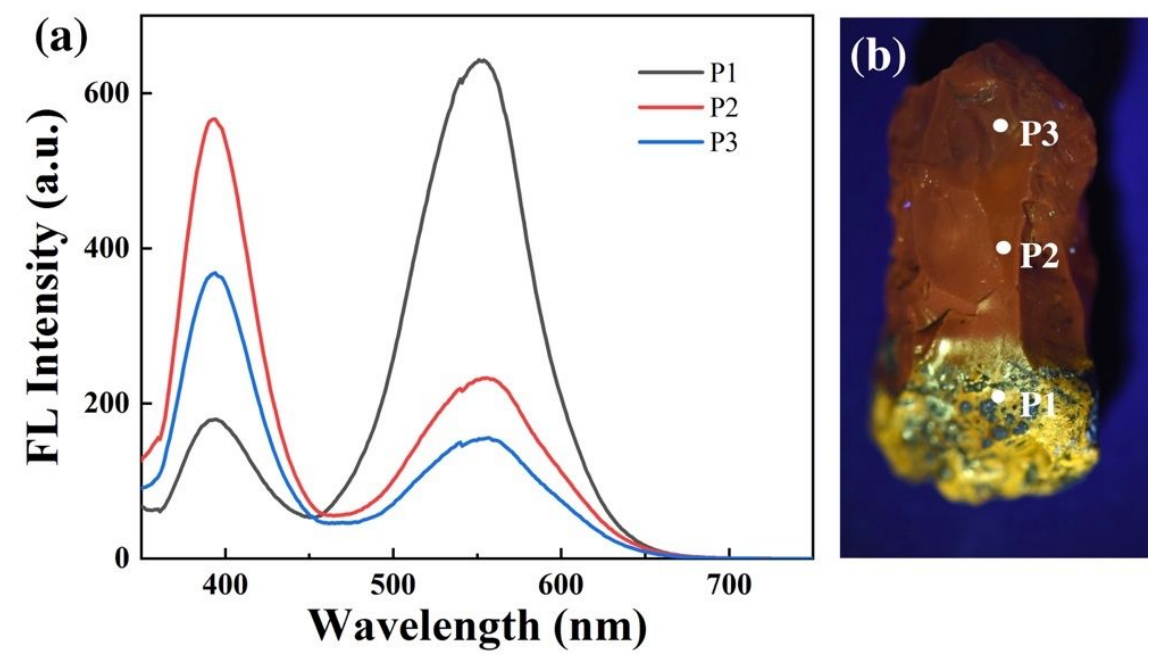
Figure S4. (a) Fluorescence spectra of the S7 sample; (b) Yellow fluorescence of S7 sample under $365 \mathrm{~nm}$ UV light.
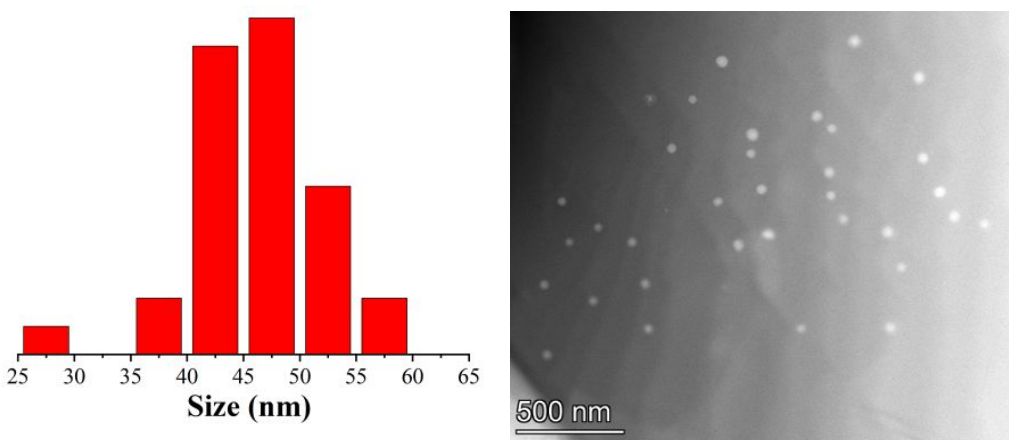

Figure S5. The size distribution of Cu NPs in plagioclase crystals.

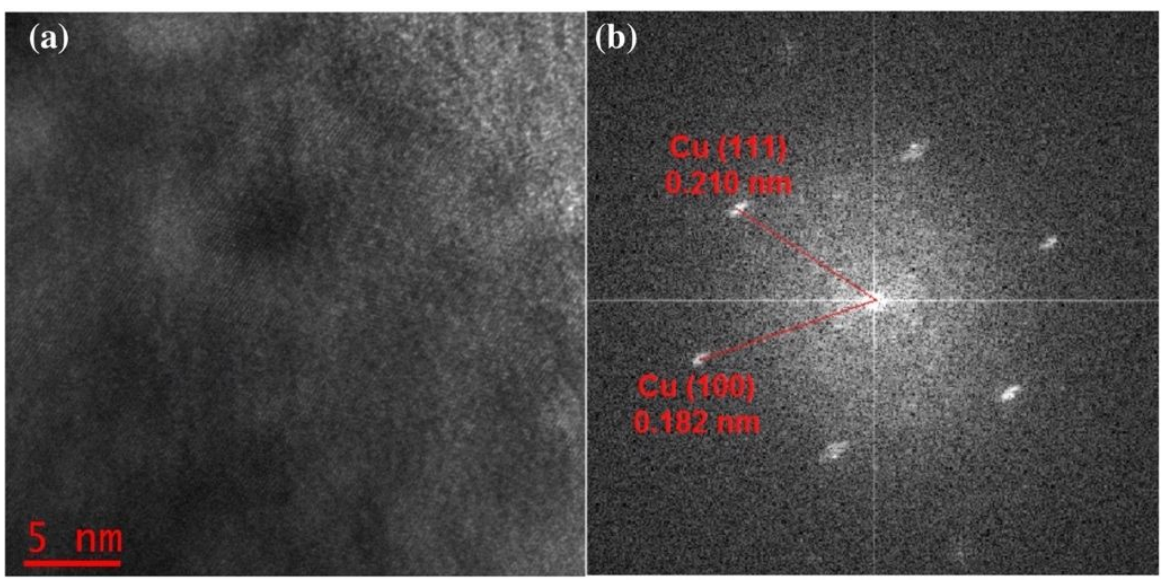

Figure S6. HRTEM image and its FFT pattern of Cu NPs in plagioclase crystals.

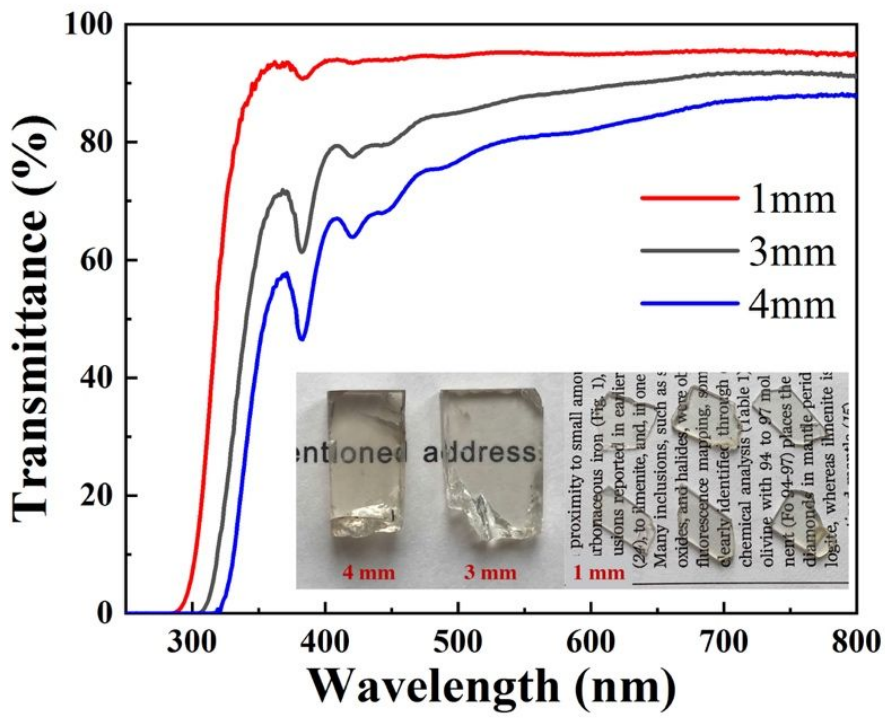

Figure S7. Transmittance spectra of polished plagioclase crystals sheets of $1 \mathrm{~mm}, 3$ $\mathrm{mm}$ and $4 \mathrm{~mm}$. 


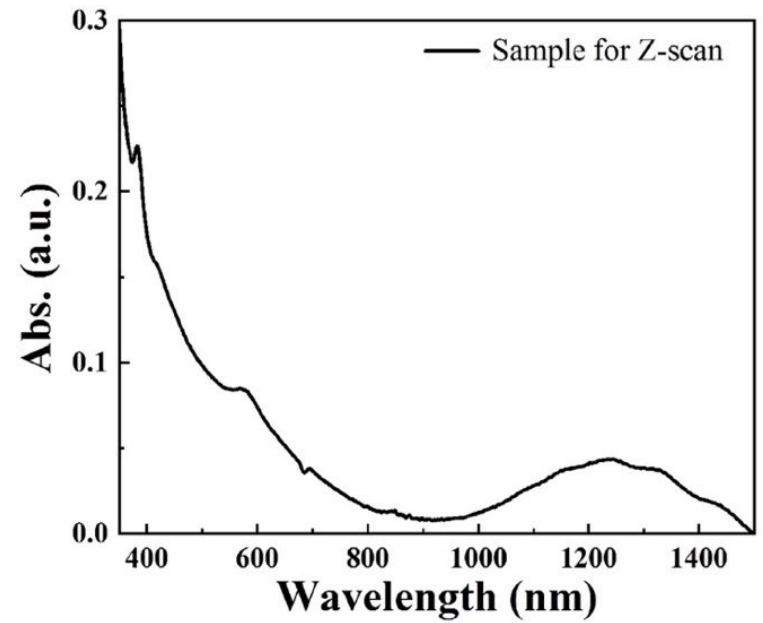

Figure S8. Linear optical absorption spectrum of the sample for Z scan test.

Table S1. LA-ICP-MS data of the Cu NPs-embedded plagioclase crystals

\begin{tabular}{cccccc}
\hline Position & $\begin{array}{c}\mathrm{Na} \\
(\mathrm{ppma})\end{array}$ & $\begin{array}{c}\mathrm{Cu} \\
(\mathrm{ppma})\end{array}$ & $\begin{array}{c}\mathrm{CaO} \\
(\mathrm{wt} \%)\end{array}$ & $\begin{array}{c}\mathrm{Al}_{2} \mathrm{O}_{3} \\
(\mathrm{wt} \%)\end{array}$ & $\begin{array}{c}\mathrm{SiO}_{2} \\
(\mathrm{wt} \%)\end{array}$ \\
\hline P1 & 18967 & 7852 & 14.12 & 30.79 & 48.50 \\
P2 & 22972 & 4975 & 13.04 & 29.75 & 50.53 \\
P3 & 24077 & 620 & 13.18 & 30.79 & 51.36 \\
P4 & 24144 & 595 & 13.68 & 30.39 & 51.25 \\
P5 & 24456 & 483 & 13.21 & 30.36 & 51.79 \\
P6 & 24788 & 393 & 13.43 & 30.00 & 51.87 \\
P7 & 25235 & 221 & 13.27 & 30.52 & 51.56 \\
P8 & 25802 & 165 & 12.91 & 29.99 & 52.41 \\
\hline
\end{tabular}

Detection limits: $\mathrm{Na}$ (10.8-17.9), $\mathrm{Cu}$ (1.2-2.2), $\mathrm{CaO}$ (0.054-0.087), $\mathrm{Al}_{2} \mathrm{O}_{3}(0.00053-0.0007)$, $\mathrm{SiO}_{2}(0.095-0.153)$. 